PRACTICE CMAJ

\title{
Acute coral contact dermatitis
}

\section{Laura Miguel-Gomez MD, Pablo Fonda-Pascual MD}

Competing interests: None declared.

This article has been peer reviewed.

The authors have obtained patient consent.

Affiliation: Department of Dermatology, Hospital Universitario Ramón y Cajal, Madrid, Spain

Correspondence to: Laura Miguel-Gomez,

lmg_0007@hotmail.com

CMAJ 2016. DOI:10.1503 /cmaj.151370

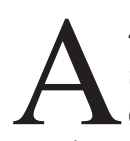

45-year-old otherwise healthy woman presented with a five-day history of a pruritic eruption on her left forearm that developed several minutes after accidentally brushing against a coral while snorkelling in the Mediterranean Sea. She reported initially feeling a stinging and burning sensation in her forearm, which was followed by the development of a reddish eruption. Physical examination revealed a well-demarcated, erythematous and serpiginous plaque on the left forearm (Figure 1). No systemic symptoms were noted. The patient had no known allergies. Based on her history and the clinical findings, acute coral contact dermatitis was diagnosed. Topical corticosteroid treatment was prescribed for 15 days, with complete resolution of the dermatitis.

Corals are marine invertebrates that belong to the phylum Cnidaria, which also includes anemones, jellyfish, sea pens and hydra. There are some species of coral that contain nematocysts, a type of organelle. When they come in contact with a foreign body, nematocysts release toxins, histamine and catecholamines, which leads to local and even systemic reactions. ${ }^{1}$

Envenomation from corals can be divided into acute and delayed hypersensitivity reactions. Acute reactions are more common and usually occur immediately or within several hours after exposure. They are characterized by bullous and edematous plaques. Delayed hypersensitivity reactions develop several days or weeks after contact with coral. They present with recurrent lichenoid papules and plaques and are considered an allergic contact dermatitis. Type I hypersensitivity reactions have been implicated in some cases. ${ }^{2,3}$ In most cases, skin lesions resolve in a few weeks with oral antihistamine and topical corticosteroid treatment.

\section{References}

1. Jefferson J, Thompson C, Hinshaw M, et al. Coral contact dermatitis. Dermatol Online J 2015;21:8.

2. Salik J, Tang R. Images in clinical medicine. Coral dermatitis. N Engl J Med 2015;373:e2.

3. Ahn HS, Yoon SY, Park HJ, et al. A patient with delayed contact dermatitis to coral and she displayed superficial granuloma. Ann Dermatol 2009;21:95-7.

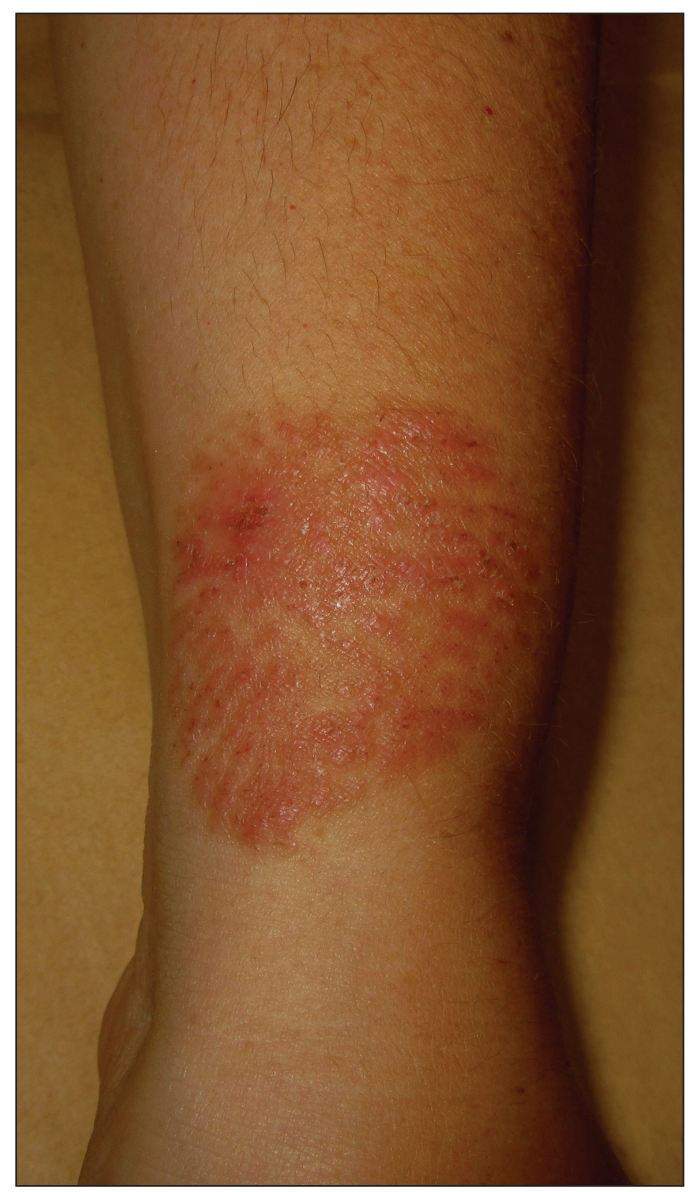

Figure 1: An erythematous and serpiginous plaque on the left forearm of a 45-year-old woman in the same area of contact with coral five days earlier while snorkelling in the Mediterranean Sea. Superficial crusts and scaly dermatitis are observed.

Clinical images are chosen because they are particularly intriguing, classic or dramatic. Submissions of clear, appropriately labelled high-resolution images must be accompanied by a figure caption and the patient's written consent for publication. A brief explanation ( 250 words maximum) of the educational significance of the images with minimal references is required. 